\title{
TERAPI LATIHAN DENGAN METODE FELDENKRAIS BERPENGARUH TERHADAP KESEIMBANGAN DINAMIS PADA LANSIA
}

\author{
Nungki Marlian Yuliadarwati \\ S1 Fisioterapi \\ Universitas Muhammadiyah Malang, Praktek UMM physio center \\ nungki@umm.ac.id \\ Auliya Vanissa \\ S1 Fisioterapi \\ Universitas Muhammadiyah Malang \\ Septiyorini \\ S1 Fisioterapi \\ RSUD Kab. Malang
}

\begin{abstract}
Abstrak: bertambahnya usia seseorang akan mengalami penurunan fungsi atau sistem fisiologis yang akan menyebabkan munculnya gangguan, seperti penurunan fisiologis yang sangat berperan dalam mengendalikan keseimbangan. Tujuan penelitian ini untuk mengetahui pengaruh latihan metode Feldenkrais terhadap keseimbangan dinamis pada lansia. Metode dalam penelitian ini menggunakan pra-eksperimental dengan pendekatan desain pretestposttest dengan satu kelompok intervensi. Time Up and Go Test (TUG) untuk mengukur keseimbangan dinamis. Analisis data dalam penelitian ini menggunakan uji Wilcoxon menggunakan program aplikasi SPSS. Hasil analisis data menunjukkan $\mathrm{P}=0,000<\alpha=$ 0,05, menunjukkan bahwa $\mathrm{H} 1$ diterima dari penelitian ini dan $\mathrm{H} 0$ ditolak. Kesimpulannya metode feldenkrais berpengaruh terhadap keseimbangan dinamis pada lansia.
\end{abstract}

Kata Kunci: $\quad$ Lansia, Keseimbangan, Feldenkrais

Sehat adalah keadaan sempurna dari fisik, mental, sosial dan bebas dari penyakit dan kelemahan. Pada usia lansia akan mengalami penurunan fungsi dalam tubuh, salah satunya penurunan fisiologis yang sangat berperan dalam mengendalikan keseimbangan seperti penurunan kekuatan otot, postur, kadar lemak yang menumpuk di daerah tertentu, dan beberapa komponen yaitu keseimbangan pada sistem visual, vestibular dan somatosensori yang terdiri dari taktil atau proprioseptif serta persepsi kognitif (Ullmann et al, 2010).

Lanjut usia (lansia) adalah seseorang yang telah mencapai masa usia lebih dari 60 tahun dengan kemampuan fisik dan kognitifnya semakin menurun. World Health Organization (WHO) menggolongkan lansia menjadi 4 yaitu usia pertengahan (middle age) adalah 45-59 tahun, lanjut usia (elderly) yaitu 60-74 tahun, lanjut usia tua (old) 75-90 tahun dan usia sangat tua (very old) diatas 90 tahun (Nugroho, 2008).

Penurunan keseimbangan pada lansia di India tercatat $13 \%$ usia 65-69 tahun dan lebih dari $46 \%$ berusia 85 tahun atau lebih (Bipinbhai, 2013). Lansia beresiko mengalami gangguan keseimbangan disebabkan karena gangguan penglihatan, letak titik berat yang tidak seimbang, faktor lingkungan dan faktor instrinsik berupa penurunan fungsi otak, propioceptive dan 
fungsi visual yang mengakibatkan terjadinya gangguan keseimbangan (Igweonu, 2010).

Keseimbangan adalah komponen penting dari aktivitas sehari-hari namun, kontrol keseimbangan sangat kompleks dan multifaktorial. Kegiatan yang dikerjakan dan lingkungan di mana individu berada dapat mempengaruhi kemampuan individu untuk mengontrol keseimbangan dengan terjadinya perubahan informasi dari tubuh dan perubahan biomekanik. Keseimbangan dapat diukur ketika tubuh memiliki BOS yang konstan atau statis, atau selama perpindahan dari satu BOS ke BOS lainnya (Bipinbhai, 2013). Keseimbangan juga didefinisikan sebagai keadaan seimbang pada tubuh yang dicapai ketika vestibular, informasi visual, dan somatosensorik terintegrasi dalam sistem saraf pusat (Ullmann et al, 2010).

Salah satu komponen pengontrol keseimbangan adalah sematosensoris, yang terdiri dari proprioceptive. Mekanisme informasi propioceptive disalurkan menuju otak melalui medula spinalis, lalu masuk ke cerebellum dan masuk kedalam kortek serbri, impuls yang masuk akan mempengaruhi kesadaran dan menjaga posisi tubuh agar tetap tegak (Ullmann et al, 2010). Faktor lain yang dapat mempengaruhi keseimbangan dinamis adalah faktor lingkugan, riwayat penyakit, kelalaian dari lansia. Akibat dari penurunan keseimbangan dinamis lansia adalah resiko jatuh, resiko jatuh akan dapat membahayakan kondisi dari lansia sendiri, seperti fraktur dan shok.

Beberapa jenis olahraga dapat meningkatkan tingkat kesehatan untuk lansia termasuk keseimbangan, fungsional, kecemasan dan mengurangi risiko jatuh (Vrantsidis et al, 2009). Beberapa cara memperbaiki dan meningkatkan keseimbangan dinamis pada lanisa adalah terapi latihan, latihan konsentrasi, sterengtening, streching dan lain-lain. Salah satu modalitas Terapi latihan yaitu Metode Feldenkrais menunjukkan hasil yang positif dan signifikan untuk diterapkan pada lansia dengan gangguan keseimbangan dinamis (Palmer, 2017). Metode Feldenkrais merupakan suatu latihan ringan dengan memanfaatkan konsentrasi kesadaran tubuh, keseimbangan,streching, dan keamanan yang sangat cocok untuk lansia (Vrantsidis et al, 2009).

Terapi latihan dengan metode Feldenkrais menggunakan pendekatan pembelajaran functional Integration untuk membantu seseorang bergerak dengan lebih mudah, nyaman dan efisien (Connors \& Nichols, 2011). Metode ini melibatkan sejumlah gerakan keseimbangan dinamis yang bertujuan untuk meningkatkan kemudahan berjalan dan bangun dari kursi (Vrantsidis et al, 2009).

Gerakan yang menekankan kontrol, koordinasi serta fungsi gerakan melalui pengulangan input dari sistem motorik sensorik dengan menggunakan suatu gerakan yang dipengaruhi oleh proprioceptif, sensasi, kontrol dan koordinasi gerakan dengan prinsip melakukan sedikit usaha untuk bergerak dan mendapatkan hasil maksimal merupakan definisi dari metode feldenkrais (Henry et al, 2016).

Dalam penelitian ini menggunakan Time Up and Go Test (TUG) dapat mengukur keseimbangan dinamis pada lansia. Ada empat rangkaian test yang dilakukan untuk mengukur keseimbangan dinamis. Lansia dikatakan memiliki gangguan keseimbangan dinamis apabila lebih dari 13,5 detik untuk menyelesaikan tugas tersebut (Palmer, 2017).

\section{METODE}

Subjek penelitian berjumlah 32 lansia di Rejoso dusun, Jawa Timur, Indonesia. Peneltian ini menggunakan metode Preexperimental one group pretest and posttest design. Keseimbangan diukur sebelum dan sesudah dengan uji keseimbangan Time $U p$ and Go Test (TUG). Uji normalitas 
menggunakan Kolmogorov Smirnov dan analisis data pengaruh menggunakan uji Wilcoxon.

\section{HASIL}

Terapi latihan dengan metode feldenkrais untuk tingkat keseimbangan pada lansia di Rejoso Desa, Kota Batu. Penelitian ini dilakukan selama empat minggu dan dimulai pada bulan April, dan Mei 2019, dan 32 sampel. Kemudian 32 sampel diberikan intervensi latihan yang dilakukan 3 kali seminggu dalam satu bulan. Dosis setiap latihan yang diberikan delapan kali hitungan dengan tiga repetisi (Igweonu, 2010).

Hasil analisis statistik dengan uji Wilcoxon diperoleh $\mathrm{P}=0,000<\alpha=0,05$, dapat disimpulkan bahwa ada pengaruh terapi latihan dengan metode feldenkrais pada keseimbangan dinamis lansia di Dusun Rejoso.

\section{PEMBAHASAN}

Kesimbangan pada perempuan lebih rendah dibandingkan laki-laki, karena perempuan mengalami menopause yang akan mengalami penurunan kadar estrogen yang menyebabkan kepadatan tulang berkurang sehingga tulang menjadi rapuh yang mempengaruhi perubahan sistem muskuloskletal mengakibatkan keseimbangan tubuh perempuan menjadi cepat menurun.(Ullmann et al, 2010).

Lansia yang mengalami penurunan keseimbangan dinamis dapat diatasi dengan modalitas terapi latihan yaitu metode feldekrais dapat digunakan untuk meningkatkan kesadaran akan gerakan dan motor control atau menggerakkan tubuh dengan efisiensi maksimal tetapi dengan tenaga minimal. Menggerakkan tubuh dengan minimal resistensi dimana metabolisme tubuh perlu bekerja lebih sedikit, dengan demikian akan menghasilkan energi yang optimal untuk melakukan sebuah gerakan menjadi efisien dengan mengoptimalkan koordinasi, kekuatan otot, keseimbangan dan pengguanaan waktu yang efisien. Gerakan dapat dikontrol dengan baik bersama dengan intensitas, kecepatan, irama dan intonasi gerakan (Henry et al, 2016).

Terapi latihan adalah sebuah fungsi yang tidak hanya dipengaruhi oleh tubuh, tetapi juga pikiran dan keduanya tidak harus dilihat secara terpisah tetapi secara keseluruhan. Metode ini mengubah kontraksi otot spindle dan mengubah sistem neuron gamma (Jain, Janssen \& DeCelle, 2004).

Sistem saraf pusat mengatur gerakan melalui kontrolnya pada sistem kerangka otot dan fasia. Gerakan harus dimulai secara ideal dan dibatasi, dengan demikian dapat meningkatkan kesadaran kepada tubuh untuk mengurangi upaya yang tidak perlu dilakukan selama melakukan sebuah gerakan. Metode feldenkrain akan menggabungkan beberapa neuromotor seperti pengulangan gerakan, perubahan kecepatan dan urutan gerakan, penggabungan pernapasan, dan lain-lain yang digunakan selama sesi latihan (Henry et al, 2016).

Pendapat lain tentang Metode Feldenkrais adalah edukasi somatik secara keseluruhan atau integral untuk meningkatkan kemampuan fungsi seseorang berdasarkan prinsip-prinsip mekanis dan neurologis yang mudah dilakukan melalui gerakan fisik dengan penyelarasan tubuh dalam ruang dan waktu, menekankan pembelajaran pengalaman suatu gerakan dengan membantu individu untuk 
mendapatkan kesadaran psiko-fisik yang tinggi, memberikan lebih banyak pilihan dan memungkinkan individu untuk membuat pilihan yang tepat tentang gerakan dan tindakan dalam melakukan aktivitas seharihari (Igweonu, 2010 dan Buchanan, 2017). Metode Feldenkrais dapat merangsang functional integration dan Awareness Through Movement (ATM) yang akan memberikan informasi ke individu agar berperan aktif dan memberikan fasilitasi untuk meningkatkan kekuatan otot (Vrantsidis et al, 2009)

Metode Feldenkrais menstimulasi awareness through movement and functional Integration untuk mengeksplorasi sistematis hubungan posisi tubuh dengan ruangan tempat seseorang berada (Jain, Jessen \& Sharon, 2004).

Terapi latihan dengan metode feldenkrais dapat terstimulasi melalui pengulangan input dari sistem motorik sensorik dengan menggunakan suatu gerakan yang dipengaruhi oleh proprioceptif, sensasi, kontrol dan koordinasi gerakan dengan prinsip melakukan sedikit usaha untuk bergerak dan mendapatkan hasil maksimal, sehingga dari permasalah keseimbangan dapat diperbaiki (Henry et al, 2016). Dengan terjadinya peningkatan body awareness akan memperbaiki sequence of movement sehingga akan memberikan feedback berupa peningkatan keseimbangan, pengoptimalan persepsi, perbaikan koordinasi, dan peningkatan kekuatan otot (Kampe, 2010).

Metode Feldenkrais menekankan pada peningkatan internal representation dan kesadaran gerak yang akan meningkatkan rasa tubuh dalam berbagai posisi atau kondisi dan dapat dilakukan sama pada sisi kanan dan sisi kiri tubuh (Connors \& Nichols, 2011). Penelitian yang sama juga menyatakan bahwa Functional Integration dan Awareness Through Movement (ATM) menggunakan gerakan yang lembut dan aman melalui serangkaian gerakan nyaman dan mudah dan secara bertahap berkembang menjadi gerakan dengan tingkat kesulitan dan kompleksitas yang lebih besar untuk meningkatkan proprioceptive, kekuatan otot secara betahap dan keseimbangan (Fonow et al, 2017).

Terapi latihan yang dilakukan dalam waktu dua hari sekali dengan melibatkan anggota gerak dari ekstremitas atas dan bawah akan merangsang/pemicu yaitu Hormon Epinefrin, grouth hormone, kortisol, sistem respirasi, sistem saraf dan sistem muskuloskeletal yang mengalami kelemahan (Yuliadarwati, 2017)

\section{SIMPULAN}

Berdasarkan hasil yang diperoleh dan penjelasan di atas, dapat disimpulkan bahwa ada pengaruh metode Feldenkrais terhadap keseimbangan dinamis pada lansia. Diharapkan penelitian lain dapat melakukan penelitian Metode Feldenkrais untuk meningkatkan keseimbangan dinamis dengan menggunakan alat ukur yang dapat diandalkan sehingga mendapatkan hasil yang lebih akurat. Diharapkan peneliti memperbanyak sampel dalam penelitian ini. Penelitian ini juga dapat digunakan sebagai literatur atau sumber untuk penelitian masa depan.

\section{SARAN}

Di hrapkan peneliti selanjutna dengan judul yang sama atau mengembangkan dengan kombinasi atau melanjutkan penelititian serupa. Dapat memperluas populasi dan menggunakan beberapa instrumen yang digunakan untuk pengukuran keseimbangan dinamis yang bertujuan untuk membuktikan keilmuan dan pengaruh dari terapi latihan dengan metode Feldenkrais, Selain itu latihan feldenkrais dapat di tindak lanjuti sebagai aktifitas yang 
dapat meningkatkan kebugaran lansia sehingga usia harapan hidup lansia lebih panjang.

\section{DAFTAR PUSTAKA}

Bipinbhai. M. P. D. (2013). Effectiveness of The Alexander Techniaue And The Feldenkrais Techniaue For Imnroving The Bodv Balance In Older Adults: A Comparative Dissertation. Nitte Universitv).

Buchanan. P. A. (2012). The feldenkrais method $($ of somatic education. In $A$ compendium of essays on alternative therapv. IntechOpen.

Connors. K. A.. Pile. C.. \& Nichols. M. E. (2011). Does the Feldenkrais Method make a difference? An investigation into the use of outcome measurement tools for evaluating changes in clients. Journal of bodvwork and movement therapies, 15(4), 446-452.

Connors, K. A., Pile, C., \& Nichols, M. E. (2011). Does the Feldenkrais Method make a difference? An investigation into the use of outcome measurement tools for evaluating changes in clients. Journal of bodywork and movement therapies, 15(4), 446-452.

Fonow. M. M.. Cook. J. A., Goldsand. R.. \& Burke-Miller. J. K. (2017). Imnlications of the Feldenkrais Method of Somatic Education for Training College Students to be Transformational Leaders. Journal of Education \& Social Policy Vol. 4, No. 3 .

Henrv. L. J.. Paungmali. A.. Mohan. V.. \& Ramli. A. (2016). Feldenkrais method and movement education-an alternate therapy in musculoskeletal rehabilitation. Polish annals of medicine. 23(1). 68-74.

Igweonu. K. (2010). Feldenkrais Method in nerformer training: encouraging curiosity and exnerimentation.

Jain. S.. Janssen. K.. \& DeCelle. S. (2004). Alexander techniaue and Feldenkrais method: a critical overview. Phvsical Medicine and Rehabilitation Clinics, 15(4), 811-825.

Kampe, T. H. O. M. A. S. (2010). Weave: The Feldenkrais Method as Choreographic Process. Perfformio, 1(2), 34-52.

Palmer. C. F. (2017). Feldenkrais movement lessons improve older adults' awareness. comfort. and function. Gerontologv and Geriatric Medicine, 3, 2333721417724014.

Ullmann. G.. Williams. H. G.. Hussev. J.. Durstine. J. L.. \& McClenaghan. B. A. (2010). Effects of Feldenkrais exercises on balance. mobilitv. balance confidence. and gait performance in communitvdwelling adults age 65 and older. The Journal of Alternative and Complementary Medicine, 16(1), 97-105.

Vrantsidis, F., Hill, K., Moore, K. J., Webb, R., Hunt, S., \& Dowson, L. (2009). Effectiveness and acceptability of Feldenkrais in improving balance related outcomes for older people: a randomised trial. Journal on Aging and Physical Activity, 17, 57-76.

Yuliadarwati, N. Marlian. (2017). The Effect OF Exercise Therapy ON Pain IN Mother After Section Caesarea. Health Science International Conference: Atlantis Press, Vol 